\title{
Clozapine Reverses the Spatial Working Memory Deficits Induced by FG7142 in Monkeys
}

Beth L. Murphy, M.S., Robert H. Roth, Ph.D., and Amy F. T. Arnsten, Ph.D.

The atypical neuroleptic, clozapine, has been shown to have encouraging, but mixed, effects on prefrontal cortical (PFC) cognitive deficits in schizophrenia, a stressexacerbated disorder involving dopamine (DA) dysregulation. The current study examined the effects of acute clozapine pretreatment on the spatial working memory deficits induced by the pharmacological stressor, FG7142, in monkeys. Previous research has shown that FG7142 impairs spatial working memory in rats and monkeys through excessive DA receptor stimulation in the PFC (Murphy et al. 1996). Lower clozapine doses (1-3 mg/kg p.o.) reversed the
FG7142-induced spatial working memory deficits, whereas doses in the clinical range (e.g., $6 \mathrm{mg} / \mathrm{kg}$, p.o.) did not improve cognitive function in most animals. Clozapine alone produced a dose-related impairment in delayed response performance. These results from nonhuman primates suggest that the clozapine doses commonly used to treat schizophrenia may not be optimal for treating the PFC cognitive deficits associated with this illness.

[Neuropsychopharmacology 16:433-437, 1997]

(C) 1997 American College of Neuropsychopharmacology
KEY WORDS: Prefrontal cortex; Dopamine; Schizophrenia; Delayed response task; Cognition; Stress

Prefrontal cortical (PFC) cognitive deficits are prominent in schizophrenia (e.g., Levin 1984; Weinberger et al. 1986; Goldman-Rakic 1991), a disorder that appears to involve dysregulation of mesocortical dopamine (DA) systems (Deutch 1992; Dolan et al. 1995; discussed in Arnsten 1997). Schizophrenia is exacerbated and/or precipitated by stress (Breier et al. 1991; Bebbington et al. 1993), a condition known to increase PFC DA turnover (Thierry et al. 1976; Deutch and Roth 1990; Murphy et al. 1996). Although recent evidence suggests that atypical neuroleptics such as clozapine may be more efficacious

From the Departments of Pharmacology (BLM, RHR), and Psychiatry (RHR), and the Section of Neurobiology (AFTA), Yale Medical School, New Haven, Connecticut.

Address correspondence to: Amy F. T. Arnsten, Ph.D., Section of Neurobiology, Yale Medical School, P.O. Box 208001, C303 SHM, New Haven, CT 06520-8001.

Received August 19, 1996; accepted November 22, 1996. than traditional neuroleptics in ameliorating cognitive deficits in schizophrenia, the results of clozapine's effects on neuropsychological performance remain equivocal (Meltzer 1992; Goldberg et al. 1993; Hagger et al. 1993; Lee et al. 1994; Goldberg and Weinberger 1994).

Recent research in nonhuman primates and rodents indicates that there is a narrow range of DA receptor stimulation for optimal PFC cognitive function (Murphy et al. 1994, 1996) and for neuronal firing patterns relevant to memory (Williams and Goldman-Rakic 1995), suggesting that there may be a correspondingly restricted dose range for DA treatment of cognitive deficits in humans. Studies in experimental animals demonstrate that either too little (Brozoski et al. 1979; Sawaguchi and Goldman-Rakic 1991; Arnsten et al. 1994) or too much (Arnsten and Goldman-Rakic 1990; Murphy et al. 1994, 1996; Verma and Moghaddam 1996; Zahrt et al. 1996) DA receptor stimulation in the PFC impairs spatial working memory performance. For example, the degree of cognitive impairment induced by the anxiogenic $\beta$-carboline, FG7142, correlates with increased DA turnover in 
the rodent PFC. Furthermore, these FG7142-induced cognitive deficits in rats and monkeys can be reversed by pretreatment with the DA antagonists haloperidol, SCH23390, or clozapine (Murphy et al. 1994, 1996).

Given the interest in clozapine's effects on cognition, the current study was designed to characterize the effects of clozapine pretreatment on the FG7142-impaired delayed response performance in rhesus monkeys. Clozapine doses ranged from $1-6 \mathrm{mg} / \mathrm{kg}$, p.o., the upper end of this range being comparable to doses given clinically.

\section{MATERIALS AND METHODS}

The methods used in this study are described in detail in Arnsten et al. 1994 and Murphy et al. 1996.

\section{Subjects}

Four female rhesus monkeys (Macaca mulatta) were used in this study, estimated to range in age from 3-12 years of age. This age range spans periadolescence to mature adulthood. All animals had been used in previous studies of FG7142 response to DA receptor antagonist treatments (Murphy et al. 1996).

\section{Delayed Response Testing}

Spatial delayed response testing (two-well) was performed in a Wisconsin General test Apparatus. Testing occurred every 3-4 days (e.g., Monday and Thursday); each session consisted of 30 trials. Animals performed at approximately $83 \%$ correct, thus leaving room for either improvement or impairment in performance. Changes in behavior were evaluated during cognitive testing by an experimenter who was familiar with the animal but "blind" to the drug treatment conditions. Sedation and agitation were rated as described previously (Arnsten et al. 1994).

\section{Drug Administration}

Clozapine (1-6 mg/kg; Sandoz, East Hanover, NJ) was mixed in a vehicle of rice cereal and chocolate syrup and fed to the animal $1 \mathrm{~h}$ before cognitive testing. FG7142 (0.2 mg/kg; RBI, Natick, MA) was suspended in a sterile saline vehicle containing $20 \%$ ethanol and injected intramuscularly $35 \mathrm{~min}$ before testing. Washout periods of at least 10 days were utilized between drug treatments. Using this design, there were no changes noted in the response to FG7142 or clozapine over time.

\section{Data Analysis}

Statistical analyses used repeated measures designs: multiple comparisons were analyzed using analysis of variance (1-ANOVA-R), and single comparisons were analyzed with a dependent $t$-test (T-dep). Statistical analysis was performed on a Macintosh LC III using Systat software.

\section{RESULTS}

FG7142 $(0.2 \mathrm{mg} / \mathrm{kg})$ significantly impaired delayed response performance compared to vehicle control (Figure 1 ; T-dep $=4.4, d f=3, p=.02$ ). Some animals showed notable signs of agitation after FG7142 treatment.

As can be seen in Figures 1A and 1C, a low, optimal dose of clozapine between $1-3 \mathrm{mg} / \mathrm{kg}$ (mean of $2.0 \pm$ $0.47 \mathrm{mg} / \mathrm{kg}$ ) could be found for each monkey, which significantly ameliorated the effects of FG7142 on delayed response performance (vehicle + FG7142 vs. clozapine + FG7142: T-dep $=3.12, d f=3, p=.05)$. These low doses of clozapine did not significantly alter performance when given on their own (Figure 1A; vehicle + vehicle vs. clozapine + vehicle: T-dep $=1.48, d f=3, p=$ .23), although one monkey's (\#613) optimal clozapine dose $(2.0 \mathrm{mg} / \mathrm{kg})$ impaired performance by $17 \%$ when given on its own.

Increasing the dose of clozapine resulted in a failure to reverse the impairment induced by FG7142 (Figures $1 \mathrm{~B}, 1 \mathrm{C})$. As can be seen in Figure 1B, the $6 \mathrm{mg} / \mathrm{kg}$ clozapine dose did not significantly ameliorate the deficits induced by FG7142 (vehicle + FG7142 vs. clozapine + FG7142: T-dep $=0.13, d f=3, p=.9$ ). Some animals exhibited moderate agitation and/or sedation with these treatments. Although $6.0 \mathrm{mg} / \mathrm{kg}$ dose was optimal for the youngest monkey, the remaining three monkeys exhibited impaired performance after $6.0 \mathrm{mg} / \mathrm{kg}$ clozapine + FG7142 treatment.

The $6.0 \mathrm{mg} / \mathrm{kg}$ dose of clozapine by itself impaired delayed response performance in both peri-adolescent and mature adult monkeys (Figure 1B; T-dep $=3.45, d f$ $=3, p=.04$ ) and produced marked agitation and/or sedation in several animals. However, these side effects did not appear to wholly account for the failure of higher clozapine doses to reverse the FG7142 response, as intermediate doses that produced no cognitive impairment and few side effects were similarly ineffective in reversing the FG7142 response in some monkeys (e.g., Figure 1 C, $3 \mathrm{mg} / \mathrm{kg}$, agitation score of -1 , "more alert than usual").

\section{DISCUSSION}

The results of this study suggest that lower clozapine doses can ameliorate spatial working memory deficits induced by FG7142, whereas doses in the clinical range are often too high for restoring stress-impaired PFC cognitive function. These findings in monkeys suggest 
A. LOW DOSES OF CLOZAPINE VS. FG7142

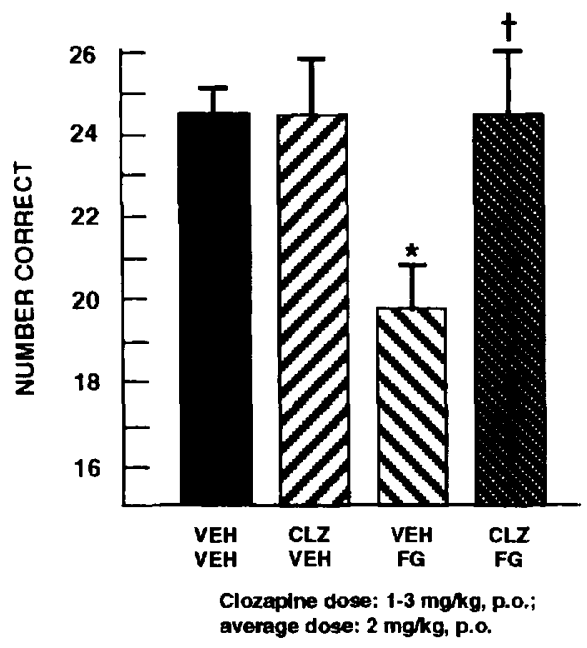

\section{B. A HIGHER DOSE OF CLOZAPINE VS. FG7142}

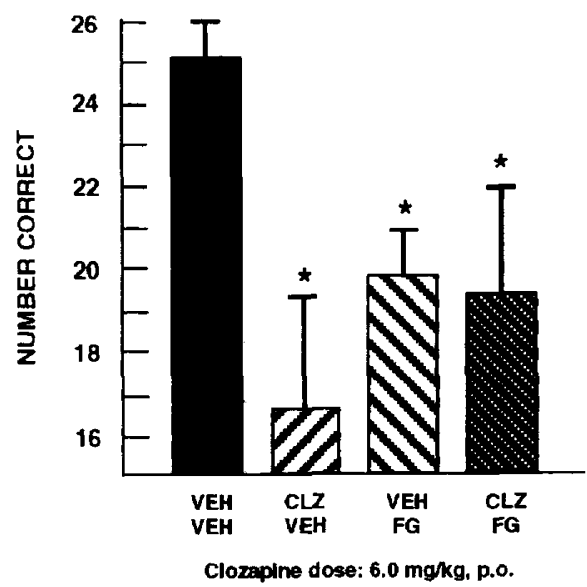

C. DOSE/RESPONSE CURVES (Monkey \#643)

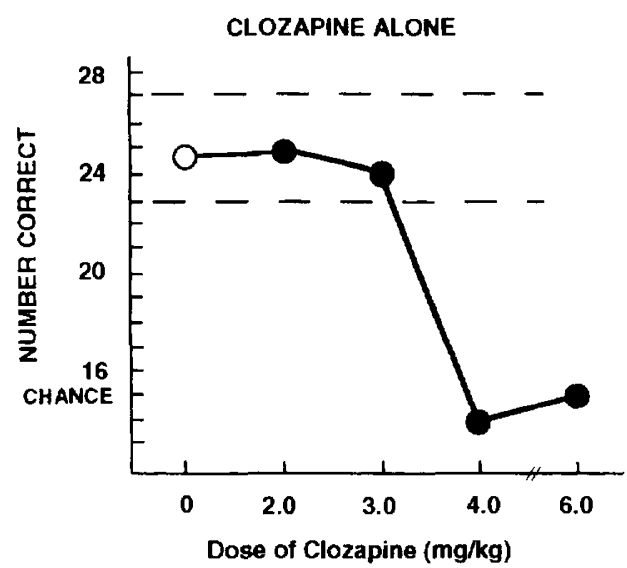

CLOZAPINE + FG7142

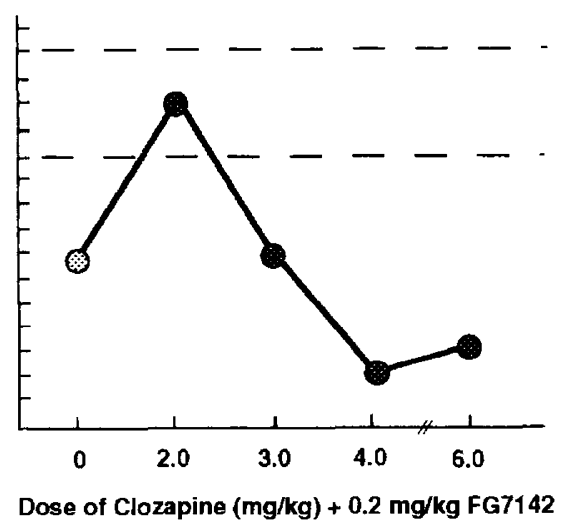

Figure 1. (A) Pretreatment with a low dose of clozapine $(1-3 \mathrm{mg} / \mathrm{kg}$, p.o.) significantly reversed the cognitive impairment induced by FG7142 $(0.2 \mathrm{mg} / \mathrm{kg})$ in monkeys $(n=4)$. Results represent mean \pm SEM trials correct out of a possible 30 trials. (B) Pretreatment with a higher dose of clozapine $(6 \mathrm{mg} / \mathrm{kg}, \mathrm{p} . \mathrm{o})$ did not reverse the cognitive impairment induced by FG7142 $(0.2 \mathrm{mg} / \mathrm{kg})$ in monkeys $(n=4)$. Results represent mean \pm SEM trials correct out of a possible 30 trials. (C) Dose-response curves of a representative mature adult monkey (\#643) showing the effects of clozapine treatment alone (left graph) and in combination with FG7142 (right graph). The $2.0 \mathrm{mg} / \mathrm{kg}$ clozapine dose reversed the effects of FG7142; higher clozapine doses were not beneficial. Results represent number of trials correct out of a possible 30 trials. The range of performance after vehicle + vehicle treatment is indicated by the dashed lines. $\mathrm{VEH}=$ vehicle; $\mathrm{CLZ}=$ clozapine; FG = FG7142; ${ }^{*}$ significantly different from vehicle + vehicle treatment; tsignificantly different from vehicle + FG7142 treatment.

that clozapine's mixed effects on cognitive deficits in schizophrenic patients may result from the clozapine dose being too high for optimal cognitive function in many patients. More research is needed with adolescent vs. mature adult monkeys to determine whether age contributes to the variation in clozapine's potency in reversing the FG7142 response. An effect of age would be of particular interest, given the recent finding of hyperdopaminergic innervation of the PFC in adolescent monkeys (Rosenberg and Lewis 1994).
The mechanisms underlying clozapine's beneficial effects on the FG7142 response are currently being explored. It is unlikely that clozapine's beneficial effects resulted from its ability to increase DA release in the PFC, as (1) these properties would be expected to worsen rather than ameliorate the FG7142 response and (2) the clozapine doses used to reverse the FG7142 response in rats (Murphy et al. 1996) are lower than doses needed to increase DA release in rodent PFC (Yamamoto et al. 1994). It is more likely that clozapine's 
beneficial effects arise from its blockade of DA receptors. We have previously shown that a $D_{1}$ receptor antagonist fully reversed the FG7142 response in rats and monkeys (Murphy et al. 1996), suggesting that clozapine's $D_{1}$ receptor blocking properties may be involved. The $D_{2}$ receptor family may also contribute to the cognitive deficits observed with FG7142 treatment. Preliminary results in rats indicate that the $D_{2} / D_{3}$ receptor antagonist, sulpiride, is effective in reversing the cognitive deficits induced by FG7142 (B. Murphy, doctoral thesis). Studies of $\mathrm{D}_{4}$ or $5 \mathrm{HT}_{2 \mathrm{~A}}$ selective antagonist pretreatment on the FG7142 response will be of particular interest given clozapine's high affinity for these sites (Meltzer et al. 1989; van Tol et al. 1991). The receptor mechanisms underlying clozapine's detrimental actions at higher doses are also relevant. Higher clozapine doses might impair performance through a number of mechanisms, including cholinergic or $\alpha_{2}$ adrenergic receptor blockade, and/or through excessive blockade of other DA receptors. Better understanding of the mechanisms underlying clozapine's beneficial versus detrimental effects on cognitive function should be helpful in the design of treatments for PFC cognitive disorders. Furthermore, the results presented here suggest that it may be worthwhile for clinicians to titrate clozapine dosage in an attempt to maximize the cognitive benefits of clozapine.

\section{REFERENCES}

Arnsten AFT (1997): Catecholamine regulation of prefrontal cortex. J Psychopharmacol 11:151-162

Arnsten AFT, Goldman-Rakic PS (1990): Stress impairs prefrontal cortex cognitive function in monkeys: Role of dopamine. Soc Neurosci Abstr 16:164

Arnsten AFT, Cai JX, Murphy BL, Goldman-Rakic PS (1994): Dopamine D1 receptor mechanisms in the cognitive performance of young adult and aged monkeys. Psychopharmacology 116:143-151

Bebbington P, Wilkins S, Jones P, Foerster A, Murray R, Toone B, Shon L (1993): Life events and psychosis. Initial results from the Camberwell collaborative psychosis study. Br J Psych 162:72-79

Breier A, Wolkowitz OM, Pickar D (1991): Stress and Schizophrenia. Advances in neuropsychiatry and psychopharmacology. In Tamminga CA, Schult SC (eds), Vol 1: Schizophrenia Research. New York, Raven Press, pp. 141-152

Brozoski T, Brown RM, Rosvold HE, Goldman PS (1979): Cognitive deficit caused by regional depletion of dopamine in prefrontal cortex of rhesus monkey. Science 205:929-931

Deutch AY (1992): The regulation of subcortical dopamine systems by the prefrontal cortex: Interactions of central dopamine systems and the pathogenesis of schizophrenia. J Neural Transm 36(S): 61-89

Deutch AY, Roth RH (1990): The determinants of stress- induced activation of the prefrontal cortical dopamine system. Prog Brain Res 85:367-403

Dolan RJ, Fletcher PC, Frith CD, Friston KJ, Frackowiak RSJ, Grasby PM (1995): Dopaminergic modulation of impaired cognitive activation of the anterior cingulate cortex in schizophrenia. Nature 378:180-182

Goldberg TE, Greenberg RD, Griffin SJ, Gold JM, Kleinman JE, Pickar D, Schulz SC, Weinberger DR (1993): The effect of clozapine on cognition and psychiatric symptoms in patients with schizophrenia. Br J Psychiatry $162: 43-48$

Goldberg TE, Weinberger DR (1994): The effects of clozapine on neurocognition: An overview. J Clin Psychiatry 55 (Suppl B): 88-90

Goldman-Rakic (1991): Prefrontal cortical dysfunction in schizophrenia: The relevance of working memory. In Carroll BJ, Barrett JE (eds), Psychopathology and the Brain. New York, Raven Press, pp 1-23.

Hagger C, Buckley P, Kenny JT, Friedman L, Ubogy D, Meltzer HY (1993): Improvement in cognitive functions and psychiatric symptoms in treatment-refractory schizophrenic patients receiving clozapine. Biol Psychiatry 34:702-712

Lee MA, Thompson PA, Meltzer HY (1994): Effects of clozapine on cognitive function in schizophrenia. J Clin Psychiatry 55 (Suppl B):82-87

Levin S (1984): Frontal lobe dysfunction in schizophrenia. II. Impairments of psychological and brain functions. J Psychiat Res 18:27-55

Meltzer HY (1992): Dimensions of outcome with clozapine. Br J Psychiatry 160 (Suppl 17):46-53

Meltzer HY, Matsubara S, Lee JC (1989): Classification of typical and atypical antipsychotic drugs on the basis of dopamine D1, D2 and serotonin2 pKi values. J Pharmacol Exp Ther 251:238-246

Murphy BL, Roth RH, Arnsten AFT (1994): The effects of FG7142 on prefrontal cortical dopamine and spatial working memory in rat and monkey. Soc Neurosci Abstr 20:1019

Murphy BL, Arnsten AFT, Goldman-Rakic PS, Roth RH (1996): Increased dopamine turnover in the prefrontal cortex impairs spatial working memory performance in rats and monkeys. Proc Nat Acad Sci USA 93:1325-1329

Murphy BL (1997): Doctoral thesis. Prefrontal cortical dopamine regulation and its cognitive correlates. New Haven, CT, Yale University

Rosenberg DR, Lewis DA (1994): Changes in the dopaminergic innervation of monkey prefrontal cortex during late postnatal development: A tyrosine hydroxylase immunohistochemical study. Biol Psychiatry 36:272-277

Sawaguchi T, Goldman-Rakic PS (1991): D1 dopamine receptors in prefrontal cortex: Involvement in working memory. Science 251:947-950

Thierry AM, Tassin JP, Blanc G, Glowinski J (1976): Selective activation of the mesocortical DA system by stress. Nature 263:242-244

van Tol HHM, Bunzow JR, Guan H-C, Sunahara RK, Seeman P, Niznik HB, Civelli O (1991): Cloning of the gene for a human dopamine D4 receptor with high affinity for the antipsychotic clozapine. Nature 350:610-614

Verma A, Moghaddam B (1996): NMDA receptor antago- 
nists impair prefrontal cortex function as assessed by spatial delayed alternation performance in rats: Modulation by dopamine. J Neurosci 16:373-379

Weinberger DR, Berman KF, Zec RF (1986): Physiologic dysfunction of dorsolateral prefrontal cortex in schizophrenia. I. Regional cerebral blood flow evidence. Arch Gen Psych 43:114-124

Williams GV, Goldman-Rakic PS (1995): Modulation of memory fields by dopamine D1 receptors in prefrontal cortex. Nature 376:572-575

Yamamoto BK, Pehek EA, Meltzer HY (1994): Brain region effects of clozapine on amino acid and monoamine transmission. J Clin Psych 55:8-14

Zahrt J, Taylor JR, Arnsten AFT (1996): Supranormal stimulation of dopamine D1 receptors in the prefrontal cortex impairs spatial working memory in rats. Soc Neurosci Abst 22:1128 